\title{
Pachamama: estudo comparativo como instrumento de reflexão dos direitos dos povos e comunidades tradicionais no Brasil
}

\author{
Pachamama: comparative study as a tool for reflection \\ on the law of traditional communities in Brazil
}

\author{
Joaquim Shiraishi Neto* \\ Marlon Araujo \\ Rosirene Martins Lima ${ }^{* * *}$
}

\section{Resumo}

Este artigo é o resultado parcial de pesquisa comparada envolvendo os países da Bolívia e do Equador, com apoio do CNPq. O presente texto objetiva refletir sobre os obstáculos e os desafios jurídicos a serem enfrentados pelos povos e comunidades tradicionais do Brasil para a efetivação de seus direitos, tomando como referência o direito construído pelos diversos grupos étnicos da Bolívia e do Equador, fundamentado no "vivir bien" e "buen vivir".

Palavras-chave: Povos e comunidades tradicionais. Direito comparado. "Vivir bien" e "buen vivir".

Este artigo representa uma primeira síntese das reflexões do projeto "Construindo novas sensibilidades jurídicas: a proteção do conhecimento tradicional associado à biodiversidade na Bolívia e no Equador à luz das transformações jurídicas recentes", com apoio do CNPq.

* Advogado. Professor visitante da Universidade Federal do Maranhão (UFMA), vinculado ao Programa de Pós-Graduação em Direito. Pesquisador CNPq e FAPEMA. Bolsista Produtividade 2 CNPq. Membro fundador da Associação de Advogados Populares da Amazônia (AAPA). Este artigo representa uma primeira síntese das reflexões do Projeto "Construindo novas sensibilidades jurídicas: a proteção do conhecimento tradicional associado à biodiversidade na Bolívia e no Equador à luz das transformações jurídicas recentes", com apoio do CNPq. E-mail: jshiraishi@uol.com.br.

*** Advogado. Mestre em Direito pela UFPA. Pesquisador do Projeto "Construindo novas sensibilidades jurídicas: a proteção do conhecimento tradicional associado à biodiversidade na Bolívia e no Equador à luz das transformações jurídicas recentes", com apoio do CNPq. E-mail: advmarlon@gmail.com.

*tor* Professora do curso de Ciências Sociais da Universidade Estadual do Maranhão (UEMA). Doutora em Meio Ambiente e Desenvolvimento. Pesquisadora do Projeto "Construindo novas sensibilidades jurídicas: a proteção do conhecimento tradicional associado à biodiversidade na Bolívia e no Equador à luz das transformações jurídicas recentes", com apoio do CNPq. E-mail: rosirenelima@uol.com.br. 


\section{Abstract}

This article is partly the result of a comparative research involving the countries of Bolivia and Ecuador, with support from CNPq. This article reflects on the obstacles and legal challenges to be faced by traditional peoples and communities in Brazil for the realization of their rights, taking as reference the law built by various ethnic groups in Bolivia and Ecuador, based on "vivir bien" and "buen vivir".

Keywords: Peoples and traditional communities. Comparative law. "Vivir bien" and "buen vivir".

\section{Introdução}

A escolha de análise do direito da Bolívia e do Equador levou em consideração as transformações jurídicas de cada um desses países nas últimas décadas, influenciadas pelas convenções e declarações internacionais (ANAYA, 2005). Para além do reconhecimento meramente formal da diversidade social, a Bolívia e o Equador realizaram profundas reformas constitucionais ao se reconhecerem como "Estados plurinacionais", reafirmando o "pluralismo jurídico igualitário". As medidas adotadas expressam uma ruptura em relação às noções tradicionais de Estado, Nação e Direito, vividas como processo de "descolonização". Tal processo vem tornando possível (re)encontrar o lugar dos diversos grupos étnicos no interior da sociedade nacional.

As situações vividas tanto pelo Equador como pela Bolívia em muito se assemelham ao que ocorre nos demais países da América Latina (GIRAUDO, 2007; GARAVITO ${ }^{1}$, 2011). Fajardo (2009), analisando esse processo, procura descrevê-lo a partir da noção de "ciclos jurídicos", quando os países passaram a adotar e incorporar em seus

Para Garavito (2011), o que ocorre na América Latina se constituiu em um novo mapa do pensamento jurídico latino-americano. 
ordenamentos jurídicos dispositivos de reconhecimento dos grupos étnicos emergentes ${ }^{2}$. Com distintas variações entre os países, esses ciclos foram assim descritos:

a) o primeiro ciclo, relacionado ao reconhecimento da existência social de grupos sociais (Brasil 1988 - reconheceu expressamente os povos indígenas e quilombolas - artigos 231 e 68, do ADCT, respectivamente);

b) o segundo, influenciado pela Convenção n. ${ }^{\circ} 169$, da OIT, de 1989, corresponderia ao reconhecimento da pluralidade étnica pelo Estado e sua proteção (Colômbia, 1991; Peru, 1993; Bolívia, 1994; Equador, 1998);

c) o terceiro ciclo, em torno do marco da Declaração das Nações Unidas sobre os Direitos Humanos dos Povos Indígenas, obedeceria ao período em que os Estados passaram a se definir como "plurinacionais", afirmando o "pluralismo jurídico igualitário” (Equador, 2008; Bolívia, 2009).

No contexto de reconhecimento do direito dos grupos sociais, o Brasil apresenta uma particularidade em relação aos demais países da América Latina que merece ser destacada, pois, em vez de reformar a sua Constituição - a exemplo do que ocorreu com a Bolívia e o Equador, conferindo plenos direitos aos grupos sociais emergentes -, vem conferindo proteção jurídica aos grupos por meio da edição de dispositivos jurídicos localizados (que se encontram referidos ao âmbito da esfera do poder público municipal) ${ }^{3}$. As análises recentes desse processo remetem a emergência dos grupos sociais aos conflitos em torno da autonomia e dos direitos territoriais ameaçados por fazendeiros, empresas e grandes empreendimentos (SHIRAISHI NETO, 2011).

2 No contexto das transformações jurídicas, verificou-se o que tem sido chamado de "judicialização da política", com diferentes resultados nos países. Sobre a análise desses processos na América Latina, consultar Sieder, Schjolden e Angell (2005).

3 Contudo, não ignoramos as medidas adotadas recentemente pelo governo brasileiro, como o Decreto n. ${ }^{\circ} 6.040$, de 7 de fevereiro de 2007, que "institui a Política Nacional de Desenvolvimento Sustentável dos Povos e Comunidades Tradicionais". A propósito das medidas políticas adotadas pelo Brasil, ver Shiraishi Neto (2007). 
O estudo comparado não se ocupou em sinalizar a "melhoria" do direito brasileiro a partir das "descobertas" realizadas durante a pesquisa, ainda em andamento ${ }^{4}$. A análise das situações jurídicas do Equador e da Bolívia tem se voltado para o que Geertz (1989) denomina de "descrição densa". A sua adoção permite afastar-se dos problemas postos em torno do direito comparado, como a sua função meramente "utilitária", obstáculo à própria produção do conhecimento científico, como diria Bachelard (1996). A ideia de "descrição densa", tomada como pressuposto metodológico da pesquisa, alinha-se às preocupações dos estudiosos do direito comparado, que propõe o exercício da comparação pelos métodos das ciências sociais, diante da insuficiência ou mesmo inexistência de métodos comparados nas ciências jurídicas (MERRYMAN, 1976; 1983).

No caso, o estudo comparativo das situações jurídicas vividas na Bolívia e no Equador permitiu refletir sobre os obstáculos e desafios jurídicos a serem enfrentados pelos povos e comunidades tradicionais do Brasil para a efetivação de seus direitos constitucionalmente garantidos. Em outras palavras, o conhecimento de outra situação jurídica forneceu instrumentos para uma reflexão acurada a respeito do direito dos povos e comunidades tradicionais no Brasil.

Dessa forma, com o objetivo de cumprir os objetivos há pouco explicitados, o presente trabalho se organiza em três tópicos. No primeiro, a reflexão se detém a uma crítica à universalidade dos Direitos Humanos; no segundo e terceiro tópicos, a análise se ocupa da relação do direito dos grupos sociais emergentes com o próprio direito. Hodiernamente, as dificuldades dessa relação se tornaram evidentes,

\footnotetext{
Nesse período da execução da pesquisa, estamos organizando o trabalho de campo. No mês de julho de 2013, iremos à La Paz e Sucre, na Bolívia, e em setembro, a Quito, no Equador. O trabalho de campo consiste na coleta de informações junto às fontes secundárias e primárias, esta última por meio de técnicas de observação direta e entrevistas semiestruturadas com a liderança dos grupos étnicos de ambos os países. O objetivo do trabalho de campo consiste em descrever o processo de incorporação dos dispositivos jurídicos nacionais e internacionais nesses países a partir da ação dos diferentes grupos sociais emergentes.
} 
por outro lado, o tamanho desse distanciamento sinaliza para as dificuldades em se promover a efetividade plena dos direitos destinados aos povos e comunidades tradicionais.

\section{Direitos humanos: particularizar o universal}

Observa-se que, a despeito do processo vivido pelos povos e comunidades tradicionais no Brasil, são diminutas as reflexões em torno de seus direitos nos meios jurídicos acadêmicos (sobretudo se considerarmos as reflexões que ocorrem nas regiões mais "centrais" do país). Isso é compreensível, na medida em que esses grupos eram considerados "invisíveis" à ordem jurídica 5 , somado ao fato do gigantesco déficit de direitos, no qual se encontrava imersa a maioria da sociedade brasileira.

Num contexto de déficit, a dogmática crítica do direito sabiamente se empenhou em construir e reafirmar a validade do princípio da dignidade da pessoa humana como princípio matriz da ordem jurídica (SILVA, 1998; ROCHA, 1999; SARLETE ${ }^{6}$, 2002). O sistema de direitos fundamentais incorporado à ordem jurídica a partir da Constituição Federal de 1988 - tida como "Constituição Cidadã" - representava um poderoso instrumento a serviço da garantia e promoção dos direitos individuais e coletivos dos indivíduos que viviam à margem da sociedade, acometidos de graves e enormes injustiças sociais. A ordem era encontrar o lugar do indivíduo na sociedade nacional, e esse lugar

5 Com raríssimas exceções, era possível identificar trabalhos jurídicos relacionados à temática, tais como: Dalmo de Abreu Dallari $(1979 ; 1980 ; 1984)$, José Afonso da Silva (1984) e Carlos Frederico Marés de Souza Filho (1982; 1983). Na sua maioria, os trabalhos procuravam refletir sobre os direitos territoriais ameaçados e a autonomia dos grupos diante das formas de tutela previstas na ordem jurídica.

6 Em trabalho recente, Sarlet (2005) retoma o princípio da dignidade da pessoa humana, atualizando esse princípio à luz dos novos padrões jurídicos. Para esse autor, o princípio da dignidade da pessoa humana é relacional, superando, assim, a discussão kantiana que fundamentava o princípio. 
implicava alçá-los à condição de "cidadão", envolucrado em um conjunto de direitos e obrigações expressos no texto constitucional de $1988^{7}$.

A polêmica gerada em torno da "morte" da Constituição dirigente envolvendo Canotilho (2001) e juristas brasileiros expressa as dificuldades em superar esse esquema de pensamento dominante ${ }^{8}$ e o tardio debate ocorrido no Brasil. Para pôr um termo às discussões, na $2^{\mathrm{a}}$ edição de sua obra A Constituição Dirigente, Canotilho (2001, p. XXIX) sintetiza as suas reflexões ao afirmar:

Em jeito de conclusão, dir-se-ia que a Constituição dirigente está morta se o dirigismo constitucional for entendido como normativismo constitucional revolucionário capaz de, por si, operar transformações emancipatórias... Numa época de cidadanias múltiplas e múltiplos de cidadania seria prejudicial aos próprios cidadãos o fecho da Constituição, erguendo-se à categoria de linha Maginot contra invasões agressivas aos direitos fundamentais. (Grifo nosso)

Para Canotilho (2001), a insuficiência do modelo jurídico até o momento adotado impossibilitaria a garantia de direitos a todos, se considerarmos que os cidadãos estão para além dos cidadãos nacionais (no caso, os portugueses). O pensamento que homogeneíza a diversidade por meio do cidadão reduz os indivíduos a uma única lógica subordinada ao sistema jurídico e econômico prevalente.

A necessidade de garantir direitos a todos implica na superação desse modelo, que se fecha para um tipo de indivíduo, o "cidadão"9.

No plano do direito, importa perceber as sucessivas mudanças da matriz do ensino jurídico, que se desloca do direito europeu para o direito norte-americano, ou seja, da dignidade da pessoa humana à liberdade. Para além de um modismo, essa modificação na forma de pensar o direito vai implicar modificações nas decisões jurídicas em disputas, cujas consequências precisam ser analisadas, sobretudo se levarmos em consideração a análise de Francisco Oliveira (1992), de que o nosso Estado de bem-estar social ruiu antes mesmo de ser efetivado.

8 No âmbito do Programa de Pós-Graduação em Direito da UFPR, foi organizado uma videoconferência com o professor Canotilho para discutir sobre a "morte" da Constituição dirigente. Os resultados desse evento foram organizados por Coutinho (2003).

9 Sobre uma crítica a esse modelo, ver Capella (1998). Para ele, o cidadão acomodado no Estado de bem-estar social se tornou servo do próprio Estado, em outras palavras, deixou de ser cidadão. 
Entretanto, é necessário recordar que o catálogo de direitos fundamentais da nossa Constituição, assim como dos demais países da América Latina, inspirados na Declaração Universal de Direitos Humanos, anuncia uma compreensão do indivíduo e de seus direitos, ou melhor, uma humanidade, espelhada na civilização europeia. Clavero (2005), criticando esse modelo de pensamento, afirma que a sua incorporação à ordem jurídica dos países latino-americanos significou, ao mesmo tempo, a "invisibilidade dos sujeitos e grupos sociais" que não se enquadravam nesse padrão de civilidade e a continuidade do colonialismo europeu que se impôs, moldando um tipo de Estado, de Nação e de Direito ${ }^{10}$.

Em países como a Bolívia e o Equador, a emergência dos grupos étnicos implicou na contestação desse modelo pretensamente universal - produto do "colonialismo europeu" - e no reconhecimento de cada um desses países como uma nação de povos, portanto, Estados plurinacionais. Nesse momento, a moldura traçada decorre das categorias nativas e das tradições dos grupos étnicos, como as noções de "vivir bien", "buen vivir" e os direitos a eles associados, envolvidos nas tradições, saberes e territorialidades. O "vivir bien" e o "buen vivir" densificam e tonificam os direitos fundamentais e demais direitos, sinalizando as transformações jurídicas vividas na Bolívia e no Equador, respectivamente. Apesar de estarem em construção, essas noções rompem com a visão de desenvolvimento baseada no crescimento econômico e progresso linear de caráter antropocêntrico. Elas implicam em uma nova forma de se conceber a relação com a

10 Para Nader e Mattei (2008, p.65), o "Estado de Direito" e as ideias que contém essa noção têm servido ao imperialismo norte-americano, na medida em que é utilizado para justificar e promover a "pilhagem" em diversas partes do mundo: "The rule of law is undoubtelly one the more poweful 'civilizing' devices used, and plunder, yesterday as today, might well be the most poweful force bhind the unfolding of the Western ideology of the rule. Most likely its power stems from persuading other societies that they lack the rule of law principle, a strategy often accompanied with the promotion of harmony as another fundamental value of civilization". 
natureza, de maneira a assegurar o bem-estar de todos os cidadãos, indistintamente ${ }^{11}$.

A recente emergência de diversos grupos sociais no Brasil (quilombolas, quebradeiras de coco, seringueiros, faxinalenses, comunidades de fundo de pastos, catadoras de mangaba...), organizados em movimentos sociais, reivindicando direitos específicos, guardam a recusa do esquema de pensamento difundido, que institui o "cidadão" como sujeito de direitos e obrigações. Vale destacar que, ainda na década de 1960, Reale (1963), estudando a sociedade brasileira, já admitia a sua pluralidade, embora suas reflexões estivessem orientadas em torno da dimensão política da liberdade em contraposição aos regimes autoritários do Leste europeu ${ }^{12}$. Diante da constatação da pluralidade social, o autor sinalizava uma preocupação próxima às discussões que circunscrevem os debates atuais:

O ideal talvez seja fazer com que as 'sociedades' se
acheguem progressivamente ao tipo de 'comunidades'. As sociedades econômicas mais produtivas são as que conseguem superar os conflitos de interesse, projetando algo de familiar, de íntimo, de confiança recíproca na vida dos sócios e dos colaboradores. (REALE, 1963, p. 238, grifo nosso)

11 Enquanto "vivir bien" está expressamente na Constituição da Bolívia de 2009, o "buen vivir" está na Constituição do Equador de 2009. Embora apareçam de forma distinta, guardam significados próximos. Em ambas as situações, trata-se de um esforço de se fazer visível os saberes, as tradições, as territorialidades, bem como as categorias dos grupos indígenas, que estavam ocultas e subjugadas pela política colonialista europeia e americana. As noções "vivir bien" e "buen vivir" trazem consigo valores, como: "reciprocidade", "harmonia", "complementariedade", "tempo cíclico", dentre tantos, que espelham as relações sociais construídas pelos grupos. Sobre "vivir bien", consultar Huanacumi (2010). Já, sobre "buen vivir", Acosta (2012); Acosta e Martinez (2009).

12 Em período recente, Silva (2007, p. 143) afirma: "A Constituição opta, pois, pela sociedade pluralista que respeita a pessoa humana e sua liberdade, em lugar de uma sociedade monista que mutila os seres e engendra as ortodoxias opressivas. O pluralismo é uma realidade, pois a sociedade se compõe de uma pluralidade de categorias sociais, de classes, grupos sociais, econômicos, culturais e ideológicos". (Grifo nosso). Diz mais: "Optar por uma sociedade pluralista significa acolher uma sociedade conflitiva, de interesses contraditórios e antagônicos", no caso, não se trata de eliminar o conflito, que longe de ser prejudicial às partes como propagam alguns autores, é salutar no processo de construção de cidadãos conscientes de seus direitos e obrigações. 
No Brasil, o aparecimento do "Outro" para o direito ocorreu a partir da hermenêutica - superando a exegese tradicional - e com os instrumentos processuais de garantia e defesa de direitos individuais e coletivos ${ }^{13}$. Em outras palavras, o "Outro", como sujeito de direitos, irrompe na paisagem do processo. Talvez seja esse o motivo pelo qual as tradições, os saberes e as territorialidades - que vinculam a existência social dos sujeitos aos modos de fazer, criar e viver (art. 216 da CF, 1988) - tenham sido relegados a um segundo plano, considerados resquícios de uma maneira primitiva de se organizar e viver ${ }^{14}$.

O desconhecimento de como é vivida a vida do "Outro" tem como corolário a relativização dos direitos, apesar de serem igualmente fundamentais, pois imprescindíveis à reprodução física, social e cultural dos grupos sociais emergentes. Exemplificando: não há como reconhecer a existência social das chamadas quebradeiras de coco babaçu e catadoras de mangaba (tal como dispõe a Lei do Estado do Maranhão n. ${ }^{\circ} 9.428$, de 2 de agosto de 2011, e a Lei do Estado do Sergipe n. ${ }^{\circ} 7.082$, de 16 de dezembro de 2010) sem Ihes garantir o livre acesso e uso das palmeiras de babaçu e da mangaba. Por ora, os despejos compulsórios, autorizados pelo Poder Judiciário, de grupos sociais para a construção de hidrelétricas, bases de lançamento de foguetes, termelétricas, portos, hotéis e resorts proclamam a face autoritária do Poder Judiciário, que, a despeito de perceber o pluralismo da sociedade brasileira, insiste em negar os direitos fundamentais desses grupos envolvidos nos empreendimentos. A face autoritária do Judiciário e o desconhecimento do "Outro" representam empecilhos na efetivação dos direitos constitucionalmente garantidos no texto de 1988.

\footnotetext{
13 A partir da análise de instrumentos processuais da Ação Civil Pública e das atribuições do Ministério Público, Gomes (1999) reafirma a diversidade da sociedade brasileira e o direito das minorias - as chamadas Ações Afirmativas.

14 Os direitos consuetudinários, que orientam as relações dos grupos no plano interno e externo, são também desconhecidos ou mal compreendidos pelos intérpretes do direito. Aliás, subordinado ao Direito Civil, o costume tem maior rigidez do que a própria regra. Nos países estudados, o reconhecimento do Outro implicou também no reconhecimento de sua forma de justiça. A esse respeito, consultar a coletânea organizada por Santos e Jiménez (2013).
} 
O enorme déficit de direitos fundamentais e a tardia descoberta do "Outro" - que ocorreu pela forma - representam obstáculos e desafios a serem enfrentados pelos grupos sociais. Optar por uma sociedade plural significa acolher os conflitos, conforme anunciou Silva (2007). Contudo, os nossos desafios se apresentam maiores pelo fato de que os direitos fundamentais inscritos na Constituição Federal de 1988 sequer foram efetivados. Assim, sob pena de os grupos sociais emergentes ficarem novamente destituídos de seus direitos, faz-se necessário garantir-lhes a sua fala como sujeitos de direitos, na medida em que ela, somente ela, pode expressar como e de que maneira vive o "Outro". Diante da diversidade social brasileira, o desafio consiste em particularizar a universalidade dos direitos humanos, a fim de que esses direitos estejam em perfeita consonância com as formas de viver do "Outro".

\section{Direitos dos povos e das comunidades tradicionais: romper as mediações}

Os problemas em torno do processo de regularização fundiária e titulação dos territórios dos povos e das comunidades tradicionais no Brasil despontam obstáculos concretos ${ }^{15}$, inclusive nas situações constitucionalmente garantidas (art. 231 e 68 do ADCT), como os territórios indígenas e quilombolas.

Como se não bastassem os obstáculos que dificultam a efetivação desse direito, observa-se uma ofensiva do agronegócio tentando obstacularizar o processo de demarcação e titulação das terras indígenas e quilombolas ${ }^{16}$. Enquanto os ruralistas encaminharam 0

\footnotetext{
15 A propósito desses obstáculos que impedem a concretização dos direitos, consultar Shiraishi Neto (2013).

16 O tamanho da ofensiva do agronegócio pode ser medido também pelo número de assassinatos de indígenas. Segundo dados: "Nos mandatos do ex-presidente Luiz Inácio Lula da Silva e nos dois primeiros anos de governo de Dilma Rousseff, 560 índios foram assassinados no país, o que dá uma média de 56 por ano. ("NúMERO..., 2013, on-line).
} 
Projeto de Emenda Constitucional (PEC) n² 215/2000, que subordina o processo de demarcação das terras indígenas ao Legislativo Nacional, retirando tal prerrogativa do Executivo, o Partido dos Democratas (DEM) encaminhou ao Supremo Tribunal Federal (STJ) uma Ação Direta de Inconstitucionalidade (Adin) contra o Decreto $n^{\circ} 4.887 / 2003$, que regulamenta o processo e identificação, reconhecimento, delimitação, demarcação e titulação das terras ocupadas por remanescentes de quilombo ${ }^{17}$. Os resultados da efetivação desses direitos estão relacionados à reestruturação do mercado formal de terras, daí as pressões exercidas por esses setores para que os territórios não sejam regularizados nem titulados, pois isso implicaria na indisposição das terras ao mercado.

A essas formas de reconhecimento territorial se somam as destinadas prevalentemente às comunidades tradicionais (seringueiros, quebradeiras de coco babaçu, catadoras de mangaba, açaizeiros, faxinalenses, comunidades de fundo de pastos...). O reconhecimento da existência social dos grupos e as medidas de proteção visando à garantia do livre acesso e uso dos recursos naturais e território ocorrem pela criação da Reserva Extrativista (Resexs) ${ }^{18}$, de competência do Instituto Chico Mendes (ICMbio), ficando esses grupos subordinados às decisões da política ambiental brasileira ${ }^{19}$.

A política ambiental vem sofrendo sucessivos deslocamentos no que tange à maneira de perceber os problemas ambientais e sua

17 A despeito dos questionamentos formulados na Adin, o Decreto $n^{\circ} 4.887 / 2003$ apresenta problemas, sobretudo pelo fato de tratar um direito étnico como se direito agrário fosse. Aliás, a maioria das ações populares propostas contra o processo de regularização fundiária e titulação dos territórios indígenas e quilombolas se baseia nos dispositivos relacionados ao direito agrário.

18 Os Projetos de Assentamento Extrativistas (Paexs), de competência do Instituto Nacional de Colonização e Reforma Agrária (INCRA), antecederam as Resexs. Eles foram implantados em alguns estados da região amazônica, mas atualmente não têm sido objeto de reivindicação por parte dos movimentos sociais.

19 As discussões em torno da proteção do conhecimento tradicional associado à biodiversidade, embora envolva diretamente sujeitos nos seus respectivos grupos sociais, ocorre no âmbito do Conselho de Gestão do Patrimônio Genético (Cegen), que é subordinado ao Ministério do Meio Ambiente. 
forma de resolvê-los ${ }^{20}$. As convenções, os protocolos e os acordos internacionais assinados e incorporados pelo Brasil revelam a influência desses dispositivos nas decisões da política ambiental brasileira. A ideia de "homogeneização jurídica", tomada emprestada de Bourdieu (2001), auxilia a compreender esse processo. Para Bourdieu (2001), na economia globalizada, há uma tentativa de se criar uma unidade jurídica com o objetivo de garantir uma maior segurança jurídica. A unificação do campo econômico tem o direito como um poderoso aliado, pois viabiliza e garante os processos em curso, regulamentando as situações e dando unidade global aos dispositivos, que facilitam o trânsito dos sujeitos e das mercadorias (recursos naturais, conhecimento tradicional e patrimônio cultural). Em termos de análise, a adoção desses dispositivos tratou de aprofundar a visão antropocêntrica, distanciando ainda mais o sujeito do objeto ${ }^{21}$, à medida que a proteção da natureza está condicionada à utilidade e ao valor econômico do objeto/recursos naturais. Os dispositivos recentes aprovados ${ }^{22}$ demonstram as transformações que atribuem novo tratamento legal à natureza, isto é, a lógica econômica que permeia a relação Homem e Natureza.

Contudo, posicionamento distinto tem sido adotado pelo Equador e pela Bolívia, a despeito de igualmente sofrerem influências dos

20 É interessante que, nas últimas eleições presidenciais, não houve por parte da sociedade nenhum estranhamento de figurar na mesma chapa uma ex-seringueira e um dos maiores empresários brasileiros. Sob o manto de uma nova proposta ambiental, essa coalização vem se sustentando. Ao se deslocar no interior do debate ambiental, Marina Silva ampliou o legue de articulações, envolvendo outros setores sociais, no entanto, distanciou-se do debate inicial, que trazia as Resexs como proposta de outro desenvolvimento para a região amazônica.

21 A modernidade ocidental transformou natureza em meio ambiente, onde o Homem reina como absoluto. A esse respeito, ver Ost (1995). Ver também o trabalho de Derani (2009) sobre a indissociabilidade entre o direito ambiental e o direito econômico.

22 Dentre elas, consultar: Lei n. ${ }^{\circ}$ 9.433, de 8 de janeiro de 1997, "Institui a Política Nacional de Recursos Hídricos, cria o Sistema Nacional de Gerenciamento de Recursos Hídricos, regulamenta o inciso XIX do art. 21 da Constituição Federal, e altera o art. $1^{\circ}$ da Lei $n^{\circ} 8.001$, de 13 de março de 1990, que modificou a Lei n. ${ }^{\circ} 7.990$, de 28 de dezembro de 1989"; e Lei n. ${ }^{\circ} 11.284$, de 2 de março de 2002, "Dispõe sobre a gestão de florestas públicas para a produção sustentável; institui, na estrutura do Ministério do Meio Ambiente, o Serviço Florestal Brasileiro - SFB; cria o Fundo Nacional de Desenvolvimento Florestal - FNDF; altera as Leis nos 10.683, de 28 de maio de 2003, 5.868, de 12 de dezembro de 1972, 9.605, de 12 de fevereiro de 1998, 4.771, de 15 de setembro de 1965, 6.938, de 31 de agosto de 1981, e 6.015, de 31 de dezembro de 1973; e dá outras providências." 
dispositivos internacionais ambientais. Ambos os países construíram e tomaram soluções particulares, rejeitando toda e qualquer medida contrária às maneiras de viver dos grupos étnicos que compõem os Estados nacionais. Os usos da natureza decorrem de uma relação harmônica norteada pelas tradições, saberes e territorialidades, não se atribuindo a natureza nenhum valor econômico. No contexto desses países, a natureza tem seus direitos e é preservada, pois é vital para a existência social dos grupos ${ }^{23}$. Tanto no Equador como na Bolívia, o texto constitucional garantiu esse significado à natureza ${ }^{24}$. Em muito se aproximam desses valores os significados das palmeiras de babaçu para as quebradeiras de coco, afinal, as palmeiras, tidas como "mães", fornecem quase tudo às mulheres e suas famílias. Tal relação com a natureza - que põe em questão a validade da política ambiental brasileira e sua universalidade - pode ser percebida em diversas situações, como na fala da quebradeira de coco Diocina Lopes, do município de Lago do Junco:

A coisa que eu mais gosto na minha vida é ir pra dentro do mato e ficar sentada um pedaço lá. Porque areja a mente da gente e a gente aprende. O melhor professor pra gente é essa universidade... não sabe? O universo! Olhar para essas florestas e pensar o que elas querem... da gente. (PORRO; SHIRAISHI NETO, 2013, p. 23, grifo nosso)

A partir do excerto, fica evidente que a maneira como Diocina Lopes expressa sua relação com a natureza antagoniza com a forma pela qual o poder público vem traçando e institucionalizando sua política ambiental. Longe de pensar e instituir medidas que possam promover essa relação harmônica, a exemplo dos países estudados, espelha-

23 Em um pronunciamento do presidente da Bolívia sobre a criação do REDD (Reducción de Emisiones por Deforestación y Degradación), Evo Morales (s.d.) se demonstra bastante crítico, pois, para ele, esse sistema objetiva transformar a natureza em mercadoria.

24 Ver o preâmbulo e os art. 10, 71, 72, 73 e 74 da Constituição do Equador de 2008. No caso da Bolívia, ver o preâmbulo e os art. 255, II, item 7, 311, II, item 3 e 403 da Constituição Bolívia de 2009. 
se em potencializar a utilização dos recursos naturais maximizando o lucro das empresas. A emergência de diversos grupos sociais e o seu reconhecimento pelo poder público, embora sinalize para a necessidade de mudanças, não vêm sendo levados em consideração. Pelo contrário, a retórica dessa política ambiental tem servido para apagar os avanços ocorridos nas últimas décadas.

A noção de desenvolvimento sustentável, que pautou as reflexões em torno da criação das primeiras Resexs na região amazônica, foi retirada do cenário por constatação de que a solução dos problemas ambientais seria a melhoria na gestão dos recursos naturais considerados finitos. O deslocamento da noção de "desenvolvimento para a gestão" compromete os princípios das lutas dos seringueiros do Acre e que originou o modelo de reserva extrativista, incorporada ao Sistema Nacional de Unidades de Conservação (SNUC) - Lei n. ${ }^{\circ}$ 9.985, de 18 de julho de 2000. A incorporação da Resex ao SNUC representou um custo não refletido pelos grupos sociais. Ela trouxe consigo um conjunto de regras alheias às práticas sociais vividas, como os planos de uso e de manejo, conselhos e gestores. Nas reservas de babaçu, os instrumentos que deveriam auxiliar o sistema de preservação da natureza e dos recursos naturais têm gerado problemas e desencontros, isto é, a lei que disciplina a criação e efetivação das Resexs, ao estabelecer uma forma de organização social externa à experiência vivida pelos próprios grupos, tem gerado uma ordem de conflitos sociais. Ressalta-se que as agências multilaterais, ao privilegiar as organizações por meio da criação de associações, têm fomentado os conflitos internos, que põem, de um lado, a tradição, e, de outro, o recurso financeiro. Nem sempre o presidente da associação representa o grupo, embora legitimamente eleito. Aliás, a adoção da associação como forma de representação coletiva do grupo tem sido imposta para diversas situações, inclusive para a titulação dos territórios quilombolas; no entanto, não podemos esquecer que o direito à associação é um direito fundamental do indivíduo, que tem a liberdade de se associar. No caso, explicitamos mais uma vez as dificuldades de se utilizar direitos individuais com intuito de promover a efetivação de direitos coletivos. 
Na década de 1990, a reserva extrativista representava uma alternativa aos projetos de reforma agrária na região amazônica. Ela concebia o seringueiro e sua família articulados com os recursos naturais e a terra. As tradições, os saberes, as territorialidades e a relação com os recursos naturais é que orientavam a criação das Resexs, pois esses elementos se vinculavam a um modo de vida conexo à reprodução física e cultural desses grupos sociais. A proposta pôs fim ao "mito da natureza intocada", que orientou a criação das primeiras unidades de conservação no Brasil. Contudo, os deslocamentos sucessivos da política ambiental brasileira vêm solapando os fundamentos primeiros, que nortearam a criação das Resexs. A criação das unidades tem privilegiado os recursos naturais, catalogando-os no estado de conservação das áreas ${ }^{25}$.

Por outro lado, os problemas em torno da expansão do modelo a outros grupos sociais da região amazônica ${ }^{26}$, como as quebradeiras de $\operatorname{coco}^{27}$, reafirma a pluralidade da sociedade brasileira destacada por Reale (1963) e Silva (2007). Mesmo havendo uma tentativa de agrupar os grupos em torno das noções "extrativitas", "povos da floresta" e "populações tradicionais", importa destacar a diversidade de sujeitos,

25 Em 2011, Joaquim Shiraishi Neto foi contratado pelo ICMbio para realização do estudo fundiário da Reserva Extrativista Enseada da Mata, no município de Penalva, no Maranhão. Nos chamados diagnósticos e relatórios, que compunham o processo, ficaram evidentes que a preocupação maior era com a descrição dos recursos naturais, "objetos", em detrimento dos sujeitos, as quebradeiras de coco. Tal postura, que objetiva a proteção a partir da utilidade dos recursos, se distancia das reflexões que nortearam a criação das primeiras Resexs no estado do Acre, onde os seringueiros protagonizavam as ações.

26 Na Amazônia, a despeito dos grupos sociais realizarem o extrativismo se assemelhando aos seringueiros, as práticas sociais são diversas. Para o seringueiro, que tem a sua "colocação", a apropriação do recurso é comum e o seu uso é privado por família; para as quebradeiras de coco, a apropriação e o uso são comuns por família. As áreas das Resexs criadas revelam as diferentes práticas sociais embutidas. Para atender o mesmo número de famílias, a área da Resex de babaçu é infinitamente menor do que a da seringa.

27 Das três reservas extrativistas de babaçu criadas nos estados do Maranhão e Tocantins, em 1992, apenas a reserva extrativista do Ciriaco foi parcialmente implantada. As demais - a reserva da Mata Grande e Extremo Norte - ainda estão em processo, sem previsão de término. Isso tem gerado muita desconfiança dos grupos em relação ao poder público, conflitos e intensificação das derrubadas das palmeiras pelos proprietários das áreas. 
grupos e práticas sociais que ensejam distintos saberes, tradições e territorialidades.

As dificuldades de regularização dos territórios das comunidades tradicionais, tal como vivem a sua vida por meio das Resexs, põem em questão a necessidade de sua reflexão. O modelo, a pretexto de preservar os recursos naturais e as comunidades tradicionais, tem imposto uma maneira que nem sempre se coaduna com as tradições, saberes, territorialidades dos grupos sociais envolvidos, em contínuo processo de transformação. A necessidade de uma ação concreta e efetiva, sem mediação, dirigida aos povos e comunidades tradicionais para a regularização e titulação de seus territórios se faz presente, sobretudo se levarmos em consideração os rumos da política ambiental brasileira, que, influenciada pelos dispositivos internacionais, tem se deslocado para conceber a natureza como recurso dotado de utilidade e valor econômico e as comunidades tradicionais como sujeitos detentores do conhecimento capazes de promover a sua preservação. A visão antropocêntrica, dominante nas discussões, reflete os resultados das políticas ambientais traçadas nos gabinetes e se distancia dos grupos sociais diretamente envolvidos. As comunidades tradicionais, as quais o Estado brasileiro reconhece como culturalmente distintas, não podem ficar à mercê da política ambiental para ter seus direitos fundamentais garantidos. As comunidades tradicionais, antes mesmo da sua consciência ecológica, possuem maneiras próprias de viver que necessitam ser preservadas.

\section{Povos e comunidades tradicionais: instituir uma agenda própria}

No contexto de reconhecimento jurídico formal dos povos e comunidades tradicionais, no Brasil, os grupos sociais emergentes não lograram a efetivação plena de seus direitos a despeito de constitucionalmente garantidos. Por sua vez, esses grupos são "convidados" a todo instante a participar das discussões e de espaços criados pelo poder público, que nem sempre contribuem para a 
concretização desses direitos. As dificuldades operacionais decorrentes de um Estado organizado a partir de um modelo de sujeito - o "cidadão" - são somadas às restrições que condicionam a aplicação do direito, a exemplo da proposta de regulamentação do direito de consulta prévia contido na Convenção n 169 da Organização Internacional do Trabalho (OIT), aprovada pelo Decreto $n^{\circ} 5.501$, de 19 de abril de 2004. Apesar de a Convenção ser um direito fundamental, portanto, de aplicação imediata e obrigação de todos, incluindo o próprio poder público, foi posta a necessidade de regulamentação do dispositivo que, de acordo com juristas e políticos, serviria para disciplinar o processo de consulta. Notadamente, o disciplinamento da consulta prévia por meio de um dispositivo servirá para restringir ao invés de ampliar o espaço de discussão política e de participação dos grupos, que serão organizados segundo uma ordem de classificação, na maioria das vezes arbitrária. A forma, no caso, deverá ser determinante e poderá se apresentar como um empecilho ao exercício efetivo desse direito. O condicionamento da participação tem consequência direta nos resultados e qualidade do processo de consulta. Pelo visto, a proposição de institucionalizar canais próprios de participação tem sido compreendida equivocadamente como mais direito.

Os povos e comunidades tradicionais estão subordinados a uma agenda política que, embora não lhes pertença, é necessária acompanhála, pois os direitos nela em jogo comprometem direta ou indiretamente a sua reprodução física e cultural. O que se constitui em problema para o poder público e demais agentes sociais nem sempre se constitui em problema aos povos e comunidades tradicionais, e isso tem provocado um hiato entre as reflexões jurídicas promovidas nos diversos espaços (meios acadêmicos e organizações não governamentais (ONGs), sobretudo) e os grupos sociais emergentes. No caso das discussões em torno do conhecimento tradicional associado à biodiversidade, os esforços em encontrar soluções jurídicas adequadas convergem para a necessidade de se criar regimes jurídicos diferenciados, sui generis, demonstrando aí a enorme crença que se tem em relação ao papel 
desse direito na garantia e efetividade dos direitos ${ }^{28}$. Por outro lado, há indústrias, laboratórios e empresas farmacêuticas e de cosmético que também sinalizam para a necessidade de regulamentação jurídica; para isso, apresentaram recentemente uma minuta de projeto, que por mais incrível que se possa parecer vem servindo como documento base para as discussões e elaboração do projeto de lei a ser apresentado ao Congresso Nacional. É visível que esses agentes sociais têm o conhecimento tradicional como mercadoria e, em nenhum momento, levando em consideração os acessos até aqui realizados, preocuparamse com uma justa e equitativa repartição dos benefícios ${ }^{29}$, como determina a Convenção da Biodiversidade Biológica (CDB), a Medida Provisória $n^{\circ}$ 2.186-16 e, recentemente, o Protocolo de Nagoya, em processo de incorporação à ordem jurídica brasileira.

As reflexões em torno do conhecimento tradicional associado à biodiversidade são exemplares a respeito da pequena participação dos grupos sociais nas decisões políticas, embora diretamente envolvidos. Para os povos e comunidades tradicionais, o conhecimento tradicional não é e nem pode ser considerado mercadoria, passível de transações mercantis. Ele é utilizado pelos grupos como forma de troca, aproximação e manutenção de laços de solidariedade e reciprocidade, sobretudo quando os grupos se sentem ameaçados. No âmbito do Movimento Interestadual das Quebradeiras de Coco Babaçu (MIQCB), a coordenadora regional de Imperatriz se dirigia às comunidades de quebradeiras de coco para ensinar a confecção da farinha do mesocarpo do babaçu, que, segundo informações difusas, teria

28 Diante da regulamentação jurídica do conhecimento tradicional promovido pela Medida Provisória n. ${ }^{\circ} 2.186-16$, de 23 de agosto de 2001, Shiraishi Neto e Dantas (2010) tecem uma crítica, pois entendem que se está diante de um processo de commoditização do conhecimento tradicional. Ou seja, o uso de velhas categorias jurídicas vinculadas ao direito privado, longe de promover uma justa e equitativa distribuição dos recursos, tende a promover a mercantilização do conhecimento tradicional associado à biodiversidade.

29 A Natura acessou o conhecimento tradicional de um grupo ligado às quebradeiras de coco, que produzia a farinha do mesocarpo. Após muita discussão e do envolvimento do Ministério Público Federal, o valor oferecido, inicialmente, se fez multiplicar, isso permitiu a criação de um fundo, repartido com as demais comunidades de quebradeiras de coco. A respeito desse processo, consultar Porro (2013). 
propriedades alimentícias e farmacêuticas. O conhecimento tradicional transmitido constitui em uma forma encontrada por essa liderança para se aproximar de outras comunidades de quebradeiras, que ainda não estão envolvidas no movimento, estabelecendo vínculos e estreitando laços. Aliás, essa prática de dispor o conhecimento tradicional e recursos naturais é comum entre as famílias das regiões Nordeste e Norte do país, inclusive nas áreas urbanas das cidades.

Na maioria das casas, é possível encontrar no quintal ervas e "plantas medicinais", cultivadas geralmente pelas mulheres, justamente para serem utilizadas em momento de "precisão" pela família, compadres e vizinhos. Quando estes estão com algum problema de saúde, solicitam ajuda e adentram no quintal para coletar a "planta" apropriada ao tratamento. Conquanto o quintal seja um espaço da casa, portanto, de domínio privado da família, é um "espaço público" na medida em que seu uso é socializado com outras famílias. Diante dessas situações, observam-se as dificuldades do direito em tentar enquadrar os fatos às suas categorias, que há muito vem dando sinais de insuficiência. Além de o conhecimento tradicional associado à biodiversidade não se constituir em problema aos grupos, como descrito, as discussões a respeito são mediadas por ONGs e pesquisadores, que nem sempre compartilham os mesmos propósitos dos grupos sociais. A não participação qualificada dos diversos grupos gera a produção de dispositivos igualmente desqualificados para atender às reais necessidades e garantias dos grupos, sobretudo se levarmos em consideração que a Convenção da Diversidade Biologia (CDB) e o Protocolo de Nagoya determinam que o país resguarde uma justa e equitativa distribuição dos recursos pelo acesso ao conhecimento tradicional.

Tais discussões sobre a necessidade de regulamentação do acesso ao conhecimento tradicional associado à biodiversidade somente têm sentido aos grupos detentores do conhecimento desde que seja garantido a eles o acesso e uso dos seus territórios, por isso mesmo faz-se urgente à efetivação dos direitos garantidos que estão previstos na Constituição Federal de 1988 e na Convenção n. ${ }^{\circ}$ 169, da OIT. De outra maneira, não assiste razão a implantação da CDB e do Protocolo 
de Nagoya sem que os grupos sociais tenham seus direitos territoriais garantidos pelo poder público. Em síntese, o direito ao território é condição fundamental para que o conhecimento tradicional seja produzido e reproduzido. A incapacidade do poder público associar as discussões entre a relação do conhecimento tradicional e os direitos territoriais vem gerando uma "amputação" do direito dos grupos sociais, que são igualmente fundamentais, portanto, indisponíveis e inalienáveis. Apesar de seus direitos fundamentais não estarem catalogados explicitamente no texto constitucional, esses direitos fundamentais podem ser extraídos da Constituição, já que ela (a Constituição Federal de 1988) reconhece a existência social de diversos grupos sociais no Brasil, que passaram de uma condição de "invisibilidade" para de "visibilidade" jurídica. Importa destacar que, em função do critério da autodefinição, são os próprios grupos que definem os alcances e limites de seus direitos, restando aos operadores ouvi-los. Isso rompe com uma concepção de direito que tem o juiz como "boca da lei". Não obstante, a adoção de qualquer medida que objetive submeter o grupo a condições que impeça a sua reprodução física e cultural constitui-se em crime, previsto na Convenção para a Prevenção e Punição de Crime de Genocídio de 1948, ratificada pelo Brasil pelo Decreto n 30.822, de 6 de maio de 1952.

\section{Conclusão}

O estudo comparativo do direito envolvendo os países do Equador e da Bolívia tem sido importante para compreender a dimensão das transformações jurídicas, que vêm ocorrendo nesses países, bem como no Brasil. Observa-se que, embora o Equador, a Bolívia e o Brasil estejam vivendo situações que se assemelham, pois envolvem o reconhecimento da diversidade social decorrente da emergência de diversos grupos, há uma grande distinção em torno dos processos. O contraste, no caso, longe de servir para promover comparações valorativas, é valido, na medida em que permite refletir sobre os rumos do próprio direito. A comparação do direito com países considerados mais atrasados é outro desafio que se põe à pesquisa desenvolvida, uma vez que essa prática de pesquisa implica romper com pré-conceitos e padrões instituídos, 
que não contribuem com as reflexões. À exceção dos antropólogos, que sempre se debruçaram em compreender as chamadas "sociedades primitivas", os estudiosos do direito sempre focalizaram seus estudos nas sociedades modernas consideradas mais avançadas, a fim de que pudessem tirar proveito dos estudos, ou seja, o direito serve de espelho ao direito da sociedade. Esse esquema de pensamento pressupõe uma linearidade de evolução e universalidade de padrões, que vem sendo contestado nas últimas décadas pelos diversos grupos sociais na América Latina.

Os processos vivenciados recentemente na América Latina, de emergência de diversos grupos étnicos, põem em questão a validade desse esquema de pensamento de pretensão universal. O seu questionamento tem gerado distintas transformações na ordem jurídica dos países, enquanto que alguns deles avançaram na positivação dos direitos, outros, nas decisões dos tribunais, revelando as preocupações de se instituir padrões mais inclusivos e justos. O certo é que transformações vêm ocorrendo, sinalizando para uma maior abertura do sistema jurídico, a fim de que ele (o sistema) possa incorporar outros sujeitos e grupos sociais até então "esquecidos" por essa mesma ordem jurídica, que se quer transformar. Em um mundo globalizado, o conhecimento desses processos é importante, pois dá condições para se refletir acerca de sua situação. O contraste, no caso dos direitos dos povos e comunidades tradicionais, serve para iluminar a compreensão dos obstáculos e dos desafios construídos, sobretudo, formas de superá-los. No caso do Brasil e demais países da América Latina, o direito tem um grande desafio que não pode ser ignorado: enfrentar os problemas ditados por uma ordem jurídica excludente e, ao mesmo tempo, estabelecer novos padrões jurídicos para beneficiar os grupos sociais emergentes, em especial os povos e comunidades tradicionais.

\section{Referências}

ACOSTA, Alberto. Buen vivir Sumak Kawsay: uma oportunidade para imaginar otros mundos. Quito: Abya Yala, 2012. 
ACOSTA, Alberto; MARTINEZ, Esperanza. EI buen vivir. uma via para el desarrollo. Quito: Abya Ayala, 2009.

ANAYA, S. James. Los pueblos indígenas em el derecho internacional. Madrid: Trotta, 2005.

BACHELARD, Gaston. A formação do espírito científico: contribuição para uma psicanálise do conhecimento. Rio de Janeiro: Contraponto, 1996.

BOURDIEU, Pierre. Contrafogos 2: por um movimento social europeu. Rio de Janeiro: Jorge Zahar, 2001.

CANOTILHO, José Joaquim Gomes. Constituição dirigente e vinculação do legislador. 2. ed. Coimbra: Coimbra Editora, 2001.

CAPELLA, Juan Ramon. Os cidadãos servos. Porto Alegre: Fabris, 1998.

COUTINHO, Jacinto Nelson de Miranda (Org.). Canotilho e a constituição dirigente. Rio de Janeiro: Renovar, 2003.

CLAVERO, Bartolomé. Presentación. Los pueblos indígenas em el derecho internacional: el capítulo de um derecho inexistente. In: ANAYA, S. James. Los pueblos indígenas em el derecho internacional. Madrid: Trotta, 2005. p. 15-22.

DALLARI, Dalmo de Abreu. O Índio, sua capacidade jurídica e suas terras: a questão da emancipação. Cadernos da Comissão Pró-índio, São Paulo, v. 1, n. 1, p. 77-82, 1979.

. Direitos sobre terras indígenas. In: DANTAS, B. Góis. Terra dos Índios Xocó: estudos e documentos. São Paulo: Comissão Pró-índio, 1980. p. 9-11.

A tutela indígena. Boletim Jurídico da Comissão Próíndio, São Paulo, ano 2, n. 4, p. 3-6, 1984.

DERANI, Cristiane. Direito ambiental econômico. São Paulo: Saraiva, 2009. 
FAJARDO, Raquel Z. Yrigoyen. Aos 20 anos do Convênio 169 da OIT: balanço e desafios da implementação dos direitos dos povos indígenas na América Latina. In: Ricardo Verdum (Org.). Povos indígenas, constituições e reformas na América Latina. Brasília: Inesc, 2009. p. 9-62.

GARAVITO, César Rodriguez. Um nuevo mapa para el pensamiento jurídico latinoamericano. In: GARAVITO, César Rodriguez EI derecho em America Latina: um mapa para el pensamiento jurídico del siglo XXI. Buenos Aires: Siglo Veintiuno, 2011. p. 11-22.

GARGARELLA, Roberto. Pensando sobre la reforma constitucional em América Latina. In: GARAVITO, César Rodriguez. El derecho em America Latina: um mapa para El pensamiento jurídico del siglo XXI. Buenos Aires: Siglo Veintiuno, 2011. p. 87-108

GEERTZ, Clifford. A interpretação das culturas. Rio de Janeiro: LTC, 1989.

GOMES, Joaquim B. Barbosa. Discriminação racial e princípio constitucional da igualdade. Revista de Informação Legislativa, Brasília, ano 36, n. 142, p. 307-323, abr./jun. 1999.

HUANACUMI, Fernando. Vivir Bien / Buen Vivir. filosofia, políticas, estratégias y experiências regionales. Bolívia: CAB, 2010.

MERRYMAN, John Henry. Hing, 2008, objeto y método del derecho comparado. Boletín Mexicano de Derecho Comparado, Cidade do México, año IX, n. ${ }^{\circ}$ 25, p.65-92, enero-agosto, 1976.

Modernización de la ciencia jurídica comparada. Boletín Mexicano de Derecho Comparado, Cidade do México, año XVI, n. 46, p.67-92, enero-abr. 1983.

MORALES, Evo. La naturaleza, los bosques y los pueblos indígenas no estamos en venta. Bolívia: [s.n.], [s.d.]. Disponível em: <http://www. bolpress.com/art.php?Cod=2010092905> Acesso em: 20 maio 2014.

NÚMERO de índios assassinados aumenta $168 \%$ nos governos Lula e Dilma, aponta jornal. Uol Cotidiano, 2013. Disponível em: <http:// 
noticias.uol.com.br/cotidiano/ultimas-noticias/2013/06/08/numero-deindios-assassinados-aumenta-168-nos-governos-lula-e-dilma-apontajornal.htm> Acesso em: 23 fev. 2014.

NADER, Lura; MATTEI, Ugo. Plunder: when the rule of law is illegal. Oxford: Blackewell Publishing, 2008.

OLIVEIRA, Francisco. Aproximações ao enigma: que quer dizer desenvolvimento local? In: SPINK, Peter; BAVA, Silvio Caccia; PAULICS, Veronika (Org.). Novos contornos da gestão local: conceitos em construção. São Paulo: Polis; Programa Gestão Pública e Cidadania/ FGV-Eaesp, 2002. p. 11-31.

OST, François. A natureza à margem da lei: ecologia à prova do direito. Lisboa: Piaget, 1995.

PORRO, Noemi; SHIRAISHI NETO, Joaquim. Mais uma luta no campo jurídico: pelo reconhecimento tradicional no modo de vida das quebradeiras de coco babaçu. São Luís: Noemi Porro, 2013.

A experiência da Coopaesp, Asasema e MIQCB com a Medida Provisória n².186/16 de 2001. São Luís: Noemi Porro, 2013. REALE, Miguel. Pluralismo e liberdade. São Paulo: Saraiva, 1963.

ROCHA, Carmen Lúcia Antunes. O princípio da dignidade da pessoa humana e a exclusão social. Revista Interesse Público, Belo Horizonte, n. 4 , p. 23-48,1999.

SANTOS, Boaventura de Souza; JIMÉNEZ, Augustín Grijalva (Ed.). Justiça indígena, plurinacionalidad e interculturalidad em Ecuador. Quito: Abya Yala, 2013.

SARLETE, Ingo Wolfgang. Dignidade da pessoa humana e direitos fundamentais na Constituição Federal de 1988. 2. ed. Porto Alegre: Livraria do Advogado, 2002.

. As dimensões da dignidade da pessoa humana: construindo uma compreensão jurídico-constitucional necessária e possível. In: . Dimensões da dignidade: ensaios de filosofia do direito 
e direito constitucional. Porto Alegre: Livraria do Advogado, 2005. p. 1343.

SIEDER, Rachel; SCHJOLDEN, Line;ANGELL, Alan. The judicialization of politics in Latin America. New York: Palgrave Macmillan, 2005.

SILVA, José Afonso da. Autoaplicabilidade do artigo 1988 da Constituição Federal. Boletim Jurídico da Comissão Pró-índio, São Paulo, ano 1, n. 3, p. 3-9, 1984.

. A dignidade da pessoa humana como valor supremo da democracia. Revista de Direito Administrativo, Belo Horizonte, $\mathrm{n}$. 212, p. 89-94, abr./jun. 1988.

Paulo: Malheiros, 2007.

. Curso de direito constitucional positivo. 29. ed. São

SHIRAISHI NETO, Joaquim. Direito dos povos e das comunidades tradicionais no Brasil: declarações, convenções internacionais e dispositivos jurídicos definidores de uma Política Nacional. Manaus: UEA, 2007.

. Novos movimentos sociais e padrões jurídicos no processo de redefinição da região amazônica. In: SHIRAISHI NETO, Joaquim et al. (Org.). Meio ambiente, território \& práticas jurídicas: enredos em conflito. São Luís: EDUFMA, 2011. p. 23-52.

. Direitos das minorias: passagem do "invisível" real para o visível formal. Manaus: UEA, 2013.

DANTAS, Fernando Antônio de Carvalho. "Commoditização" do conhecimento tradicional: notas sobre o processo de regulamentação jurídica. In: ALMEIDA, Alfredo Wagner Berno de et al. (Org.). Conhecimento tradicional: normas vigentes e propostas. 2. ed. Manaus: UEA, 2010.

SOUZA FILHO, Carlos Frederico Marés de. Alguns pontos sobre os povos indígenas e o direito. In: SANTOS, Sílvio Coelho (Org.). O índio perante o direito. Florianópolis: UFSC, 1982. p. 88-97. 
. A cidadania e os índios. In: VIDAL, L. (Org.). 0 índio e a cidadania. São Paulo: Comissão Pró-índio, 1983. p. 44-51.

Data de recebimento: 29/07/13

Data de aprovação: 17/12/13 